\begin{tabular}{l|l}
\hline \\
\end{tabular} \mid $\begin{array}{r}\text { SISTEMA } \\
\text { ELETRONNICO } \\
\text { DE REVISTAS } \\
\text { SER I UFPR }\end{array}$

\title{
Cobrança pelo uso da água no Brasil: uma revisão metodológica
}

\section{Payment for Water Use in Brazil: a Methodology Review}

Nícolas Reinaldo FINKLER ${ }^{1 *}$, Ludmilson Abritta MENDES², Taison Anderson BORTOLIN ${ }^{1}$, Vania Elisabete SCHNEIDER $^{1}$

${ }^{1}$ Universidade de Caxias do Sul (UCS), Caxias do Sul, RS, Brasil.

${ }^{2}$ Universidade Federal de Sergipe (UFS), São Cristóvão, SE, Brasil.

*E-mail de contato: nicolas.finkler@gmail.com

Artigo recebido em 5 de maio de 2014, versão final aceita em 4 de novembro de 2014.

RESUMO: A aplicação de instrumentos econômicos na gestão das águas tem como princípio incentivar a forma racional dos padrões de consumo do bem. Nesta linha a Política Nacional dos Recursos Hídricos, na busca de atribuir um valor econômico à água, introduziu a cobrança pelo uso dela nas Bacias Hidrográficas $(\mathrm{BCH})$ no Brasil. Esta revisão metodológica apresenta as metodologias de cobrança pelo uso da água atualmente empregadas em águas de domínio da União, bem como a arrecadação gerada e os investimentos realizados nas respectivas $\mathrm{BCH}$. No Brasil, o instrumento é empregado nas BCH do Rio Paraíba do Sul, dos rios Piracicaba, Capivari e Jundiaí, do Rio São Francisco e do Rio Doce. Também no Estado do Ceará, pioneiro no país, a cobrança é aplicada pelo uso da água, porém conceitualmente diferenciada. Verificou-se que em todas as BCH de águas com domínio da União, o modelo de cobrança segue a mesma estruturação, considerando todos os tipos de usos de água, principalmente a captação, o consumo e o lançamento de efluentes. Ainda, cada parcela considera os volumes utilizados, o preço unitário pelo uso, os coeficientes próprios e relativos à gestão da $\mathrm{BCH}$. Por outro lado, a cobrança pelo uso da água bruta no Estado do Ceará apresenta-se baseada no atual sistema de tarifação e é definida somente com base na água consumida. A arrecadação setorial apresentou-se variável, no entanto, pode-se citar como setores com maior potencial de arrecadação, o de saneamento básico e o industrial. Ainda, verificou-se que os investimentos realizados com recursos obtidos com a cobrança vêm sendo aplicados, em sua maioria, a ações estruturais que envolvem a recuperação dos recursos hídricos, tais como estações de tratamento e redes de coleta e afastamento de efluentes.

Palavras-chave: gestão de recursos hídricos; cobrança pelo uso da água; metodologias de cobrança.

ABSTRACT: The purpose of using economic tools in water management is to encourage reasonable water consumption patterns. In this context, the National Water Resources Policy, in order to put an economic price to water, introduced the water pricing in national Watersheds. This methodology review presents the methods for putting a price on water currently used in waters under federal jurisdiction, the generated revenues and investments 
in the respective watersheds. In Brazil, this tool is currently used in the following watersheds: Paraíba do Sul, Piracicaba, Capivari and Judiaí Rivers, São Francisco River and Rio Doce. Also in the state of Ceará, a pioneer in the country, a price is paid for water use, but in a conceptually different way. In all watersheds with waters under federal jurisdiction, the pricing model follows the same structure, encompassing all types of water use, particularly catchment, consumption and effluent discharge. Thus, each take into account the volumes used, the unitary price for the use and the own and relative management coefficients of the watershed. The price of raw water use in Ceará is calculated according to the current fare system and only defined according to the values of water consumed. The sector collection proved to be variable; however, one may say that basic sanitation and industrial sectors show greatest revenue collection potential. Thus, we found that revenues collected were mostly invested in structural actions involving the recovery of water resources, such as water treatment plants, sewage collection and waste removal.

Keywords: water resource management; water pricing; pricing methodologies.

\section{Introdução}

As águas superficiais se caracterizam como as mais vulneráveis à poluição e à escassez devido à fácil acessibilidade para o lançamento de efluentes industriais e domésticos, particularmente próximo aos aglomerados urbanos e atividades industriais. Os processos naturais como precipitação pluviométrica, erosão e carregamento de sedimentos, e os processos antropogênicos como urbanização, industrialização e agricultura, contribuem para a degradação dos recursos e corroboram para definir a qualidade de água de uma região (Thomas, 2002).

A evolução deste quadro, associado à escassez de águas próprias para a utilização, promoveu a mudança do gerenciamento da oferta de um recurso até então tido como abundante, para o gerenciamento da demanda de um recurso escasso. Neste sentido, passou-se a pensar em utilizar técnicas de gerenciamento mais eficientes, dentre estas se destaca a utilização de instrumentos econômicos (Forgiarini, 2006).

A aplicação destes instrumentos econômicos na gestão das águas tem como objetivo incentivar a forma racional dos padrões de consumo do bem. Na busca de atribuir um valor econômico à água, a Lei Federal $\mathrm{n}^{\circ}$ 9.433 (Brasil, 1997) introduziu a cobrança pelo uso da água, nas Bacias Hidrográficas $(\mathrm{BCH})$ no Brasil. Além disso, a referida legislação objetiva, através da cobrança pelo uso da água, incentivar a racionalização do uso da água e a obter recursos financeiros para o financiamento dos programas e das intervenções contemplados nos planos de recursos hídricos.
Assim sendo, o objetivo desta revisão é a apresentação do instrumento de cobrança pelo uso da água no Brasil, considerando os aspectos legais que o regulam, bem como a exposição das metodologias atualmente empregadas em águas de domínio da União e a arrecadação gerada nas respectivas $\mathrm{BCH}$.

\section{Histórico da gestão de recursos hídricos no Brasil}

A gestão dos recursos hídricos no Brasil teve início com os portugueses, os quais criaram as chamadas "Ordenações" tuteladas pelo Alvará de 1804, que tiveram como objeto a regulação dos domínios hídricos. Este determinava que os rios navegáveis e os que se faziam navegáveis, eram caudais e corriam intermitentes eram de propriedade e direito real e sua utilização dependia de concessão regia. Ainda, os recursos hídricos foram tutelados, principalmente quanto aos direitos de navegação e pesca, levando em conta a importância dessas atividades para a economia da época (Granziera, 2006; Pompeu, 2006).

Tais Ordenações tornaram-se inaplicáveis no momento da promulgação da Constituição do Império, sendo que todos os direitos reais foram transpassados para domínio público. No entanto, as diretrizes do Alvará de 1804 continuaram em vigor até o advento do Código de Águas de 1934, de caráter mais burocrático (Braga, 2006).

O Código Civil de 1916, através do seu artigo n. 68 , é caracterizado como a primeira manifestação do 
direito brasileiro que dispõe sobre a cobrança pelo uso da água. Instaurava a cobrança pela utilização dos bens públicos, conforme as respectivas leis da administração a que pertenciam (Forgiarini, 2006).

Em 1934, após 27 anos de tramitação no Congresso Nacional, foi aprovado o Código de Águas através do Decreto n. 24.643, reconhecido como o marco legal do gerenciamento dos recursos hídricos no Brasil. O Código tinha como objetivo harmonizar o uso das águas para fins de produção de energia elétrica, agricultura e demais usos (Granziera, 2006). Dito código é considerado extremamente avançado para sua época, pois introduziu termos avançados como os Princípios de Usuário-Pagador (PUP) e Poluidor-Pagador (PPP) - utilizado na Europa somente na década de 1970 - e conceituou o uso múltiplo de recursos hídricos no Brasil. Contudo, o modelo mostrou-se ineficaz e politicamente frágil. Além disso, sua implementação nunca foi efetivada (Thomas, 2002; FINEP, UFBA, 2012; Viana, 2011).

Nesta fase denominada Velho Paradigma prevaleceu um modelo de gestão de recursos hídricos setorial, centralizado e insuficiente, impulsionado principalmente pelo desenvolvimento do setor elétrico e industrial no país. A segunda fase, denominada Novo Paradigma, teve início após a promulgação da Constituição Federal de 1988 e se caracterizou como um modelo de gestão descentralizada e participativa, considerando o uso múltiplo, o valor econômico da água e tomando como unidade principal de planejamento as bacias hidrográficas (Thomas, 2002; Vianna, 2011).

Após a Constituição de 1988, outros marcos regulatórios foram criados no Brasil baseados nos novos princípios de gestão de recursos hídricos. Aqui, podem ser citadas a Lei 9.433 (Brasil, 1997), denominada Lei das Águas, instituindo a Política Nacional de Recursos Hídricos (PNRH) e criando o Sistema Nacional de Gerenciamento dos Recursos Hídricos (SNGRH), a Lei 9.984 (Brasil, 2000) ou Lei da ANA e as Leis estaduais de águas (Forgiarini, 2006). Thomas (2002) afirma que o modelo de gestão hídrica surgida com a PNRH (Brasil, 1997) é baseado no modelo francês de gerenciamento centrado no conjunto comitê/agência de bacia, no qual o comitê é o fórum de discussões tomadas de decisões e a agência, o órgão executivo e de apoio técnico.
Para os objetivos da PNRH (Brasil, 1997) serem atingidos, a Lei estabeleceu cinco instrumentos:

I - os Planos de Recursos Hídricos;

II - o enquadramento dos corpos de água em classes, segundo os usos preponderantes da água;

III - a outorga dos direitos de uso de recursos hídricos;

IV - a cobrança pelo uso de recursos hídricos;

V - o Sistema de Informações sobre Recursos Hídricos (Brasil, 1997).

A Lei também criou um novo sistema para o gerenciamento dos recursos hídricos no Brasil, composto pelas seguintes estruturas: Conselho Nacional de Recursos Hídricos (CNRH); Conselhos de Recursos Hídricos dos Estados e do Distrito Federal; Comitês de Bacias Hidrográficas; os órgãos dos poderes públicos federal, estaduais e municipais, cujas competências se relacionem com a gestão de recursos hídricos; e Agências de Água (Brasil, 1997).

A Lei Federal n. 9.984 (Brasil, 2000), conhecida como Lei da ANA, dispõe sobre a criação da Agência Nacional das Águas (ANA), entidade federal cuja finalidade é a implementação da PNRH e coordenação do SGRH. Entre suas atribuições destacam-se: outorgar o direito de uso dos recursos hídricos e implementar a cobrança pelo uso da água em rios de domínio da União, arrecadando, distribuindo e aplicando as receitas auferidas em conjunto com os comitês de bacia (Brasil, 2000). No entanto, está previsto na Lei que a ANA poderá delegar aos Comitês e às Agências as competências das atribuições acima citadas, com o objetivo de minimizar a complexidade das diferentes características apresentadas pelos recursos hídricos de domínio da União e dos Estados (Thomas, 2002).

\section{Metodologias de cobrança pelo uso da água em aplicação no país}

A seguir, serão apresentadas as metodologias de cobrança pelo uso da água, atualmente empregadas em $\mathrm{BCH}$ com águas de domínio da União: $\mathrm{BCH}$ do Rio Paraíba do Sul; BCH dos Rios Piracicaba, Capivari e Jundiaí; BCH do Rio São Francisco e BCH do Rio Doce (ANA, 2013). Também, devido à particularidade concei- 
tual, o mecanismo de cobrança pela água bruta aplicada ao Estado do Ceará será apresentado. Na Figura 1, estão localizadas as bacias hidrográficas nas quais a cobrança está implementada, bem como o Estado do Ceará.
Além disso, os valores totais arrecadados serão discorridos. É válido ressaltar que tais recursos financeiros são repassados às respectivas agências de bacias que aplicam os recursos a ações e a investimentos para

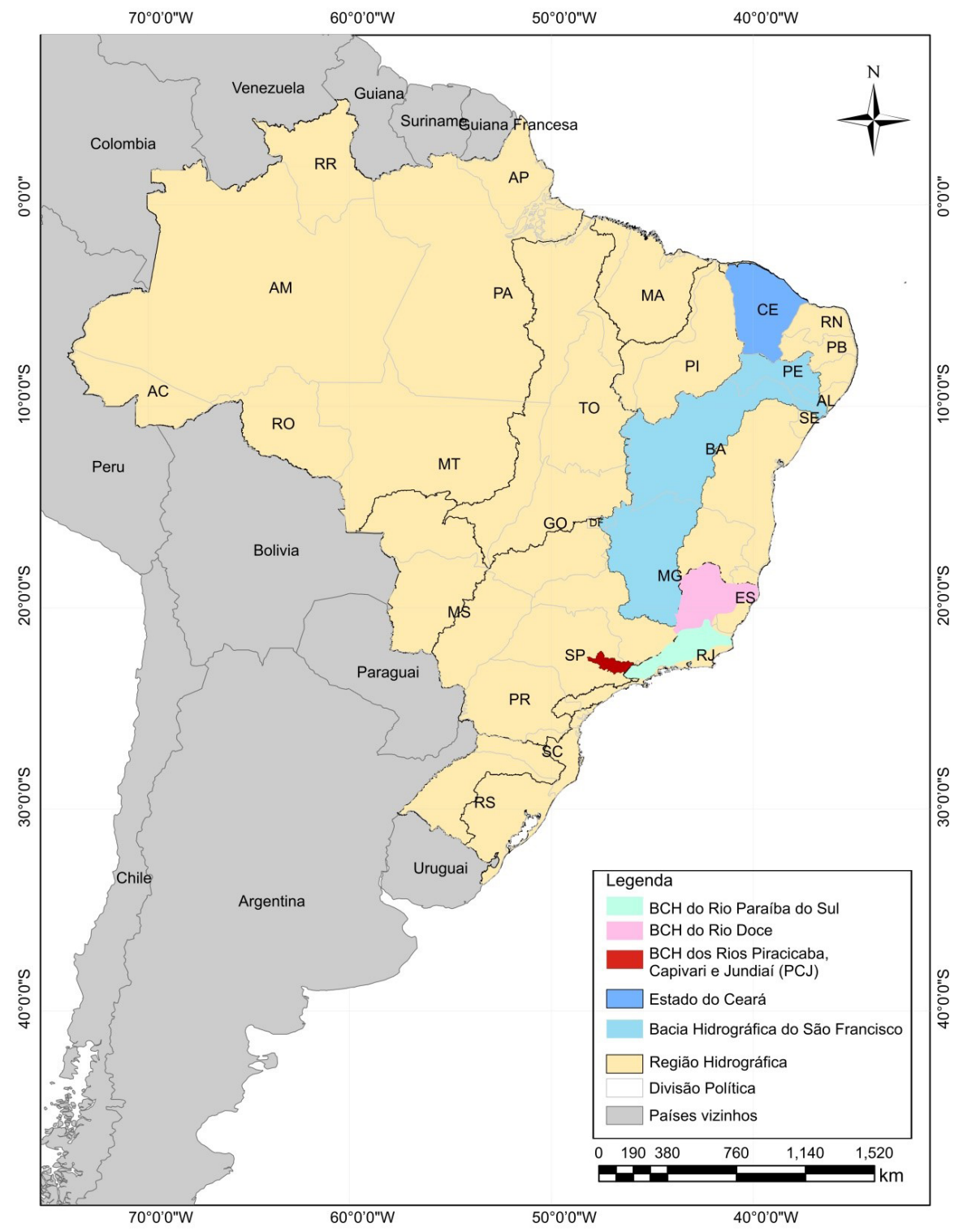

FIGURA 1 - Cobrança pelo uso da água no Brasil.

FONTE: elaborado pelos autores (2014). 
recuperação e preservação dos recursos hídricos conforme o Plano de Recursos Hídricos da $\mathrm{BCH}$, a saber: Associação Pró-Gestão das Águas da Bacia Hidrográfica do Rio Paraíba do Sul - AGEVAP; Fundação Agência das Bacias Hidrográficas dos Rios Piracicaba, Capivari e Jundiaí - Agência PCJ; Associação Executiva de Apoio à Gestão de Bacias Hidrográficas Peixe Vivo - AGB Peixe Vivo; e Instituto Bioatlântica - IBio AGB-Doce. Em relação ao Estado do Ceará, a Companhia de Gestão dos Recursos Hídricos - COGERH, uma empresa estatal, desempenha tal função.

\subsection{BCH do Rio Paraíba do Sul}

A BCH do rio Paraíba do Sul (PBS) abrange 184 municípios, sendo 39 localizados no Estado de São Paulo, 57 no estado do Rio de Janeiro e 88 em Minas Gerais. (CEIVAP, 2013a). A população da bacia é estimada em 5,5 milhões de habitantes, sendo 1,8 milhão no estado de São Paulo, 2,4 milhões no Rio de Janeiro e 1,3 em Minas Gerais. Cerca de $16 \%$ da população fluminense reside na bacia do Paraíba, contra 5\% dos paulistas e 7\% dos mineiros (IBGE, 2010).

A área de drenagem da bacia é de $62.074 \mathrm{~km}^{2}$, estendendo-se pelos estados de São Paulo $\left(14.510 \mathrm{~km}^{2}\right)$, Rio de Janeiro $\left(26.851 \mathrm{~km}^{2}\right)$ e Minas Gerais (20.713 $\mathrm{km}^{2}$ ). A área da bacia corresponde a $0,7 \%$ da área total do Brasil e, aproximadamente, a 6\% da Região Sudeste do país. No Rio de Janeiro, a bacia abrange $63 \%$ da área total do estado; em São Paulo, 5\% e em Minas Gerais, apenas 4\% (CEIVAP, 2013a).

O mecanismo de cobrança e de valores, atualmente empregados em águas de domínio federal na $\mathrm{BCH}$ do Rio Paraíba do Sul, foram instituídos pelas Deliberações CEIVAP n ${ }^{\circ}$ 65/2006 e 70/2006 (ANA, 2013).

\subsection{BCH dos Rios Piracicaba, Capivarie Jundiaí}

As BCH dos Rios Piracicaba, Capivari e Jundiaí (PCJ) somam $15.304 \mathrm{~km}^{2}$ de extensão, dos quais 92,6\% $\left(14.178 \mathrm{~km}^{2}\right)$ estão localizados no Estado de São Paulo, e $7,4 \%\left(1,126 \mathrm{~km}^{2}\right)$ no Sul de Minas Gerais. Ainda, abrangem total ou parcialmente a área territorial de 76 municípios, dos quais 62 têm sede localizada no interior da bacia, sendo 58 localizados em São Paulo e 4 em Minas Gerais. Com aproximadamente 5 milhões de habitantes, a região é considerada uma das mais importantes do Brasil devido ao seu desenvolvimento econômico, que representa cerca de 7\% do Produto Interno Bruto (PIB) Nacional. (Agência PCJ, 2013).

A cobrança pelo uso da água se iniciou em águas de domínio da União, no ano de 2006, através da Deliberação Comitês PCJ n 25/2005. Os mecanismos e valores atuais de cobrança estão estabelecidos na Deliberação Comitês PCJ no 160/2012, aprovada pela Resolução CNRH no 155/2014. São cobrados os usos de captação, de consumo, de lançamento de efluentes e de transposição de bacia de usuários sujeitos à Outorga de Direito de Uso de Recursos Hídricos com captação de água superior a $5 \mathrm{~m}^{3} /$ dia (ANA, 2013).

\section{3. $\mathrm{BCH}$ do Rio São Francisco}

A BCH do Rio São Francisco (BHSF) cobre uma área de 636,9 mil $\mathrm{km}^{2}$ (7,5\% do país), que envolve sete estados da União: Minas Gerais, Bahia, Goiás, Distrito Federal, Pernambuco, Alagoas e Sergipe, e 503 municípios (CBHSF, 2013). A população total da Bacia é de 13.297.955 habitantes, sendo 74,4\% correspondentes à população urbana e $25,6 \%$ correspondentes à população rural. O Comitê da Bacia Hidrográfica do Rio São Francisco (CBHSF) foi o terceiro comitê a implementar a cobrança pelo uso da água em rios de domínio da União, iniciada em julho de 2010. A cobrança é aplicada à captação, ao consumo, ao lançamento de efluentes e à transposição de bacias para usuários com captação superior a 4,0 1/s (ANA, 2013).

Os mecanismos e os valores atuais de cobrança estão estabelecidos na Deliberação CBHSF n ${ }^{\circ} 40 / 2008$, aprovada pela Resolução CNRH n ${ }^{\circ}$ 108/2010.

\subsection{BCH do Rio Doce}

A BCH do Rio Doce apresenta uma extensão territorial de aproximadamente $83.400 \mathrm{~km} 2$, dos quais $86 \%$ 
pertencem ao Estado de Minas Gerais e o restante ao Estado do Espírito Santo. Abrange, total ou parcialmente, áreas de 228 municípios, sendo 202 em Minas Gerais e 26 no Espírito Santo, e possui uma população total da ordem de 3,1 milhões de habitantes. A bacia abriga o maior complexo siderúrgico da América Latina. Três das cinco maiores empresas de Minas Gerais no ano de 2000, a Companhia Siderúrgica Belgo Mineira, a ACESITA e a USIMINAS, lá operam. Além disso, lá se encontra a maior mineradora a céu aberto do mundo, a Companhia Vale do Rio Doce (CBH-DOCE, 2013).

O Comitê da Bacia Hidrográfica do Rio Doce CBH-DOCE foi o quarto comitê a implementar a cobrança pelo uso da água em rios de domínio da União, iniciado em novembro de 2011. Os mecanismos e os valores atuais de cobrança estão estabelecidos na Deliberação CBH-Doce $n^{\circ} 26 / 11$ aprovada pela Resolução CNRH n ${ }^{\circ}$ 123/11. São cobrados os usos de captação, transposição e lançamento de efluentes de usuários sujeitos à Outorga de Direito de Uso de Recursos Hídricos com captação de água superior a 1,0 1/s no trecho mineiro e 1,5 1/s no trecho capixaba. Ademais, a parcela referente ao consumo não é considerada no modelo, o que gerou maior simplificação operacional e entendimento da cobrança pelo usuário pagador (ANA, 2013).

\subsection{Estado do Ceará}

O gerenciamento dos recursos hídricos de domínio do Estado do Ceará está sob a responsabilidade da Companhia de Gestão dos Recursos Hídricos (COGERH), atendendo a uma população total de 8.452.381 habitantes, distribuídas em 184 municípios em uma extensão territorial de 148.920,472 km² (IBGE, 2010).

O modelo de cobrança, aplicado sob formas e objetivos distintos dos aplicados a outras $\mathrm{BCH}$, caracteriza-se pela forma binomial fundamentada no custo marginal de gerenciamento dos recursos hídricos e na capacidade de pagamento de cada categoria de usuário. Este modelo envolve um componente referente ao consumo (tarifa de consumo) e outro equivalente à demanda outorgada (tarifa de demanda) (Vianna, 2011). Contudo, em decorrência da necessidade de estruturação do órgão de gerenciamento, da universalização da outorga, assim como de uma maior compreensão e aceitação dos usuários, a cobrança foi implementada de forma monomial, admitindo tarifas apenas definidas com base na água consumida (tarifa de consumo) (CEARÁ, 2013).O modelo atual só abrange o que Lanna (1999) classifica como preço 3 da água: “(...) um preço correspondente à retirada (...) no sentido de frear o consumo, viabilizando inclusive o investimento em dispositivos poupadores ou que aumentam a oferta de água”.

\subsection{Comparação das metodologias de cobrança pelo uso da água no Brasil}

A Tabela 1 define as variáveis utilizadas nas equações de cobrança pelo uso da água em águas de domínio da União, por sua vez, apresentadas na Tabela 2.

A partir da análise dos modelos adotados nas quatro $\mathrm{BCH}$ federais, em que a cobrança está vigente, percebe-se que os mecanismos de cobrança dividem-se entre os seguintes componentes: bases de cálculo, preços unitários e coeficientes multiplicadores (ANA, 2010). Apesar de algumas variações quanto à origem das informações relativas às quantidades (medidas ou outorgadas) e nomenclaturas das variáveis, todos os modelos apresentam a mesma estrutura (Vianna, 2011).

Nas equações aplicadas às $\mathrm{BCH}$ apresentadas, com exceção da $\mathrm{BCH}$ Rio Doce, a parcela relativa à água efetivamente consumida é considerada na cobrança pelo uso da água. Dessa forma, sinaliza ao usuário que quanto menor for o consumo, menor será o pagamento pelo uso da água.

Em relação à parcela relativa ao lançamento de carga orgânica, somente a BCH PCJ considera o coeficiente referente ao nível de tratamento de efluentes aplicado, gerando descontos a usuários que possuam sistemas de abatimento de DBO. Tal aspecto implica na busca contínua por tecnologias de tratamento visando a diminuição da poluição lançada e a consequente melhoria da qualidade da água, não presente nas demais $\mathrm{BCH}$.

$\mathrm{O}$ componente referente ao consumo pelo setor agropecuário, com exceção da $\mathrm{BCH}$ Rio Doce, está também presente nas equações das demais $\mathrm{BCH}$, seja como um coeficiente de consumo ou como um fator específico, visto que o setor representa as maiores demandas pelo uso 
TABELA 1 - Variáveis empregadas nas metodologias de cobrança pelo uso da água.

\begin{tabular}{|c|c|c|}
\hline Variável & Definição & CBH* \\
\hline $\mathrm{K}_{\text {out }}$ & Peso atribuído ao volume anual de captação outorgado & 1,2 e 4 \\
\hline $\mathrm{Q}_{\text {cap out }}$ & Volume anual de água captada conforme outorga & 1,2 e 4 \\
\hline $\mathrm{K}_{\text {med }}$ & Peso atribuído ao volume anual de captação medido & 1 \\
\hline $\mathrm{Q}_{\text {capmed }}$ & Volume anual de água captado, conforme medição & 1 \\
\hline $\mathrm{PPU}_{\mathrm{x}}$ & Preço público unitário para cada tipo de uso & 1,3 e 4 \\
\hline $\mathrm{K}_{\text {cap classe }}$ & Coeficiente relacionado à classe do corpo hídrico no ponto de captação & 1 e 4 \\
\hline$Q_{\text {cap } \mathrm{T}}$ & Volume anual de água captado total & 1 \\
\hline $\mathrm{Q}_{\text {lançT }}$ & Volume anual de água lançado total & 1 \\
\hline $\mathrm{K}_{\text {cons }}$ & Coeficiente que leva em conta a parte da água utilizada & 3 \\
\hline $\mathrm{K}_{\text {cap }}$ & Coeficiente que considera objetivos específicos pela captação & 3 \\
\hline $\mathrm{K}_{\text {lanç }}$ & Coeficiente que considera objetivos específicos pelo lançamento & 3 \\
\hline $\mathrm{K}_{\text {irrigação }}$ & Coeficiente que considera a parte da água utilizada na irrigação & 1 \\
\hline$Q_{\text {areia }}$ & Volume anual de água captado para mineração & 1 \\
\hline $\mathrm{U}$ & Teor de umidade da areia produzida & 1 \\
\hline $\mathrm{C}_{\mathrm{DBO}}$ & $\mathrm{DBO}_{5,20}$ média anual do efluente lançado & $1,2,3$ e 4 \\
\hline $\mathrm{Q}_{\text {lanc }}$ & Volume anual de água lançado 9 & 1,2 e 4 \\
\hline $\mathrm{GH} / \mathrm{EH}$ & Total anual da energia efetivamente gerada por uma $\mathrm{PCH}$ & 1 e 4 \\
\hline $\mathrm{K}_{\text {cons irrigação }}$ & Coeficiente que considera boas práticas de uso na irrigação & 3 \\
\hline $\mathrm{Q}_{\text {lanç }}$ & Volume anual de efluente lançado & $1,2,3$ e 4 \\
\hline $\mathrm{K}_{\text {prior }}$ & Coeficiente que considera a prioridade de uso estabelecida & 3 \\
\hline TAR & Tarifa Atualizada de Referência & 1 e 4 \\
\hline $\mathrm{P}$ & Percentual definido a titulo de cobrança & 1 e 4 \\
\hline $\mathrm{K}_{\text {agroepc }}$ & Coeficiente que considera as boas práticas de uso & 1 \\
\hline PUB & Preço unitário básico para cada tipo de uso & 3 \\
\hline $\mathrm{K}_{\text {sist irrigação }}$ & Coeficiente que visa quantificar a água consumida na irrigação & 2 \\
\hline $\mathrm{K}_{\text {lanç classe }}$ & Coeficiente relacionado à classe do corpo hídrico no ponto de lançamento & 2 \\
\hline $\mathrm{K}_{\mathrm{PR}}$ & Coeficiente que considera a remoção percentual de carga orgânica & 2 \\
\hline $\mathrm{K}_{\mathrm{t}}$ & Coeficiente considera as boas práticas de uso e conservação & 2 e 4 \\
\hline $\mathrm{Q}_{\text {transp out }}$ & Volume anual utilizado na transposição, conforme outorga & 2 e 4 \\
\hline $\mathrm{Q}_{\text {transpmed }}$ & Volume anual utilizado na transposição, conforme medição & 2 e 4 \\
\hline $\mathrm{K}_{\text {gestão }}$ & Coeficiente que considera o efetivo retorno à bacia dos recursos arrecadados & $1,2,3$ e 4 \\
\hline
\end{tabular}

${ }^{* 1} \mathrm{BCH}$ Paraíba do Sul; ${ }^{2} \mathrm{BCH}$ PCJ; ${ }^{3} \mathrm{BCHSF}$; e ${ }^{4} \mathrm{BCH}$ Rio Doce. 
TABELA 2 - Metodologias de cobrança pelo uso da água em aplicação no Brasil.

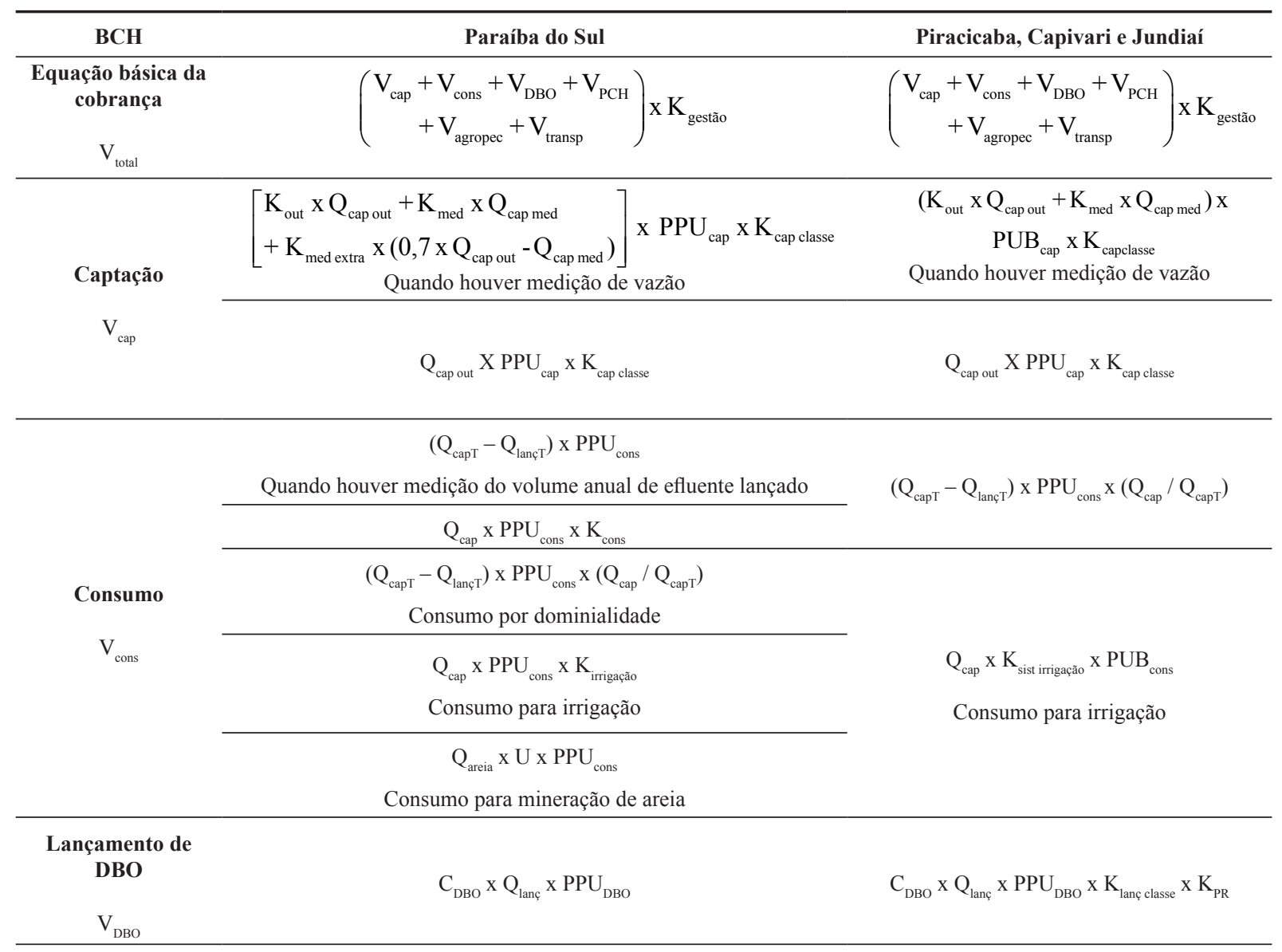

\section{Geração de energia}

elétrica

$\mathrm{V}_{\mathrm{PCH}}$
GH x TAR x P

$$
\left(\mathrm{V}_{\text {cap }}+\mathrm{V}_{\text {cons }}\right) \times \mathrm{K}_{\text {agropec }}
$$$$
\mathrm{V}_{\text {total }} * 1,15
$$

$\mathrm{BCH}$ do Rio Gandu
Calculado de acordo com o que dispuser a legislação federal e atos normativos das autoridades competentes

Agropecuário

$\mathrm{V}_{\text {agropec }}$

Transposição

$\mathrm{V}_{\text {transp }}$

$\left(\mathrm{V}_{\text {cap }}+\mathrm{V}_{\text {cons }}\right) \times \mathrm{K}_{\mathrm{t}}$

$$
\left(\mathrm{Q}_{\text {transp out }} \times \mathrm{K}_{\text {out }}\right.
$$$$
\left.+\mathrm{Q}_{\text {transp med }} \times \mathrm{K}_{\text {med }}\right) \times \mathrm{PUB}_{\text {transp }} \times \mathrm{K}_{\text {cap classe }}
$$

(continua) 
TABELA 2 - Conclusão

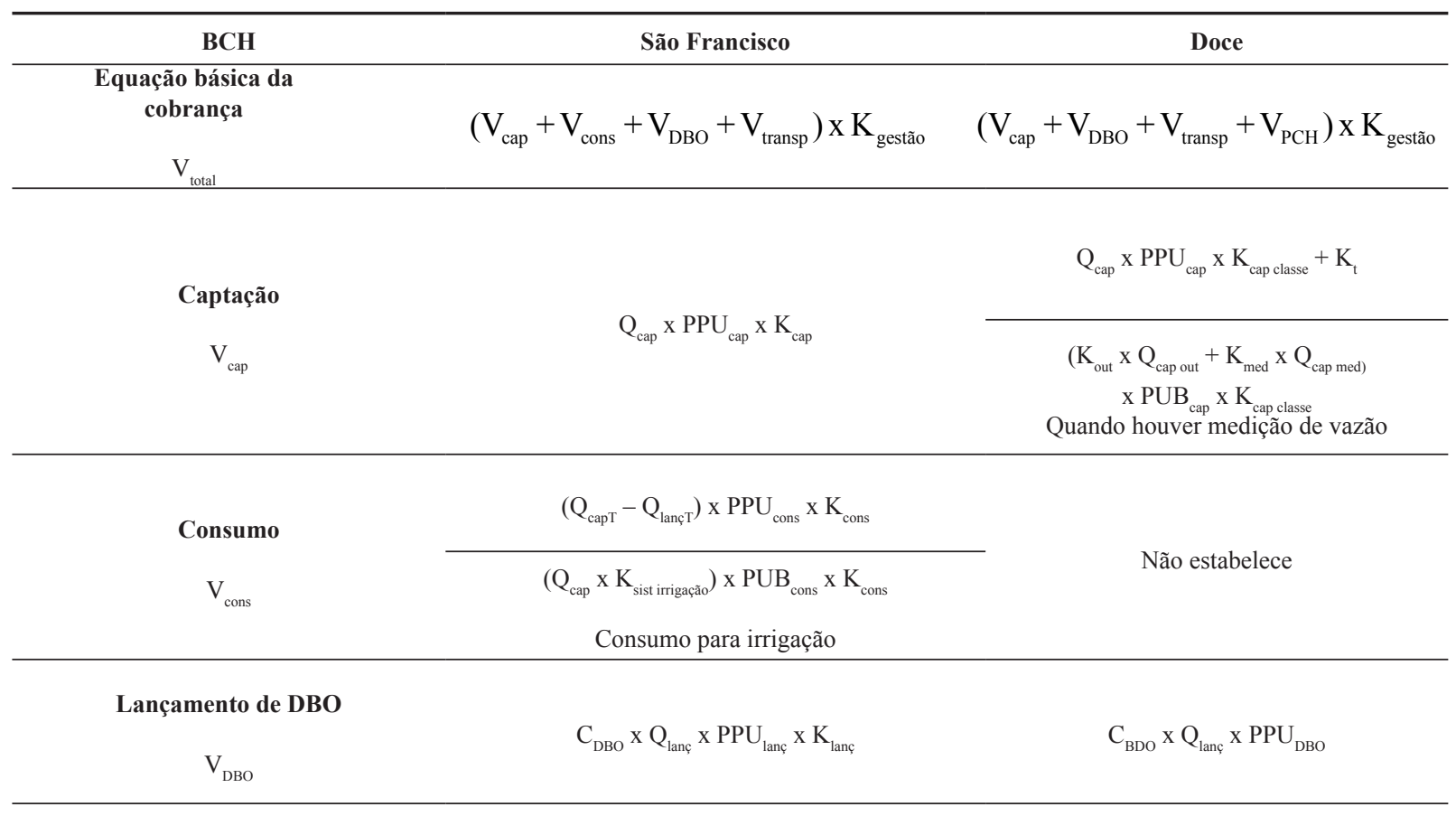

\section{Geração de energia elétrica}

$\begin{array}{lll}\mathrm{V}_{\mathrm{PCH}} & \text { Não estabelece } & \text { EH x TAR x K }\end{array}$

\section{Agropecuário}

$\mathrm{V}_{\text {agropec }}$

Não estabelece Não estabelece

\begin{tabular}{|c|c|c|}
\hline Transposição & $\begin{array}{c}\left(\mathrm{Q}_{\text {cap }} \times \mathrm{PPU}_{\text {cap }}\right. \\
\left.+\mathrm{Q}_{\text {cons }} \times \mathrm{PPU}_{\text {cons }}\right) \times \mathrm{K}_{\text {cap classe }} \times \mathrm{K}_{\text {prior }} \times \mathrm{K}_{\text {gestão }}\end{array}$ & \\
\hline $\mathrm{V}_{\text {transp }}$ & $+\mathrm{Q}_{\text {cons }} \times \mathrm{PPU}_{\text {cons }}^{\left(\mathrm{Q}_{\text {cap med }}\right) \times \mathrm{K}_{\text {cap classe }} \times \mathrm{PPU}_{\text {crior }} \times \mathrm{K}_{\text {gestão }}}$ & $\mathrm{Q}_{\text {transp }} \times \mathrm{PPU}_{\text {transp }}$ out $\times \mathrm{K}_{\text {classe }}$ \\
\hline
\end{tabular}

Quando a vazão efetivamente utilizada for superior à vazão firme outorgada

FONTES: CEIVAP (2006); PCJ (2007); CBHSF (2008); CBH-Doce (2011). 
da água. Além disso, é possível observar a presença de coeficientes de boas práticas de uso agropecuário $(\mathrm{BCH}$ PBS e BCH PCJ), que novamente sinalizam ao usuário a possibilidade de menor pagamento pelo uso da água.

Com relação aos preços unitários praticados na cobrança pelo uso das águas de domínio da União, cada Comitê determina um conjunto de valores unitários para cada tipo de uso, conforme apresentado na Tabela 3. A determinação desses valores pelos respectivos Comitês de Bacia segue, basicamente, os mesmos princípios adotados atualmente nas BCH do Paraíba do Sul e PBS. À época das negociações sobre a implantação da cobrança na $\mathrm{BCH}$ do Paraíba do Sul, foram realizadas simulações com diferentes Preços Públicos Unitários (PPU) para avaliar o potencial de arrecadação e o impacto sobre os usuários, chegando-se a valores entre $\mathrm{R} \$ 0,02 / \mathrm{m} 3$ e $\mathrm{R} \$ 0,05 / \mathrm{m} 3$. Como alguns setores alegaram dificuldades em arcar com os custos decorrentes da cobrança, o CEIVAP adotou preços diferenciados para cada setor usuário (Carvalho et al., 2007). Na BCH PCJ, a definição dos Preços Unitário Básicos (PUB) pelos Comitês PCJ também se deu por simulações do potencial de arrecadação da cobrança, porém os valores foram discriminados por tipo de uso (captação, consumo, lançamento de matéria orgânica) e não por tipo de usuário como na $\mathrm{BCH}$ do Paraíba do Sul (Carvalho et al., 2007). Em 2006, o CEIVAP passou a considerar o tipo de uso na fixação do PPU, analogamente aos Comitês PCJ na fixação do PUB. O mesmo critério também foi seguido, em linhas gerais, pelas BCH São Francisco e Doce, as quais adotaram valores unitários muito próximos aos praticados nas $\mathrm{BCH}$ do Paraíba do Sul e PCJ, conforme a Tabela 3. É valido acrescentar que os Comitês PCJ e Rio Doce, estabeleceram através de suas Resoluções, preços unitários que aumentam gradativamente em cada ano. No caso dos Comitês PCJ, a resolução estipula valores que variam no período de 2013 a 2016. No caso do Comitê Rio Doce esse período compreende o período de 2011 a 2015.

Por sua vez, a cobrança pela utilização dos recursos hídricos no Ceará foi instituída pelo Decreto n. 24.264, de 12 de novembro de 1996, foi inicialmente implementada para o uso industrial e para as concessionárias de serviço de água potável, considerando o volume em $\mathrm{m}^{3}$ efetivamente consumido (ANA, 2013). O Decreto Estadual $n^{\circ} 31.195 / 2013$ estabelece os mecanismos e os valores atualmente empregados na cobrança pelo uso da água no Estado.

A tarifa a ser cobrada pelo uso dos recursos hídricos no Estado do Ceará é calculada conforme Equação 1.

$$
T(u)=(T x V e f)
$$

Onde:

$\mathrm{T}(\mathrm{u})$ = tarifa do usuário;

$\mathrm{T}=$ tarifa padrão sobre volume consumido;

Vef $=$ volume mensal consumido pelo usuário.

No mesmo Decreto Estadual n $31.195 / 2013$, estão definidas as sete categorias de usos: 1 - abastecimento público; 2 -indústria; 3 - piscicultura; 4 - carcinicultura; 5 - água mineral e água potável de mesa; 6 - irrigação; e 7 - demais categorias de uso.

TABELA 3 - Valores unitários praticados em cada bacia hidrográfica.

\begin{tabular}{|c|c|c|c|c|}
\hline \multirow{2}{*}{ Tipo de uso da água } & \multicolumn{4}{|c|}{ Bacia Hidrográfica } \\
\hline & Paraíba do Sul & PCJ & São Francisco & Doce \\
\hline $\begin{array}{l}\text { Captação } \\
(\mathrm{R} \$ / \mathrm{m} 3)\end{array}$ & 0,01 & $0,0100-0,0127$ & 0,01 & $0,018-0,030$ \\
\hline $\begin{array}{c}\text { Consumo } \\
(\mathrm{R} \$ / \mathrm{m} 3)\end{array}$ & 0,02 & $0,0200-0,0255$ & 0,02 & - \\
\hline $\begin{array}{l}\text { Lançamento de matéria orgânica } \\
\qquad(\mathrm{R} \$ / \mathrm{kg} \mathrm{DBO})\end{array}$ & 0,07 & $0,100-0,1274$ & 0,07 & $0,100-0,160$ \\
\hline $\begin{array}{c}\text { Transposição } \\
(\mathrm{R} \$ / \mathrm{m} 3)\end{array}$ & - & $0,0150-0,0191$ & - & $0,022-0,040$ \\
\hline
\end{tabular}

FONTE: CEIVAP (2006); CBHSF (2008); CBH-Doce (2011) e PCJ (2012). 
Os valores cobrados pela água no Ceará são bastante altos quando comparados aos aplicados à Bacia do Paraíba do Sul, por exemplo, devido principalmente às características específicas da disponibilidade hídrica no estado e da natureza diversa da cobrança. As tarifas pelo uso de água bruta de domínio do Estado variam dependendo das seguintes categorias de usuários, para captação superficial e subterrânea (Tabela 4).

\subsection{Arrecadação obtida através da cobrança pelo uso da água no Brasil}

A Tabela 5 apresenta a arrecadação por setor de usuários na $\mathrm{BCH}$ Paraíba do Sul referente ao período de exercício de 2008 a 2011, com aplicação dos novos valores de PPU.

TABELA 4 - Tarifas pelo uso de água bruta para cada categoria de uso.

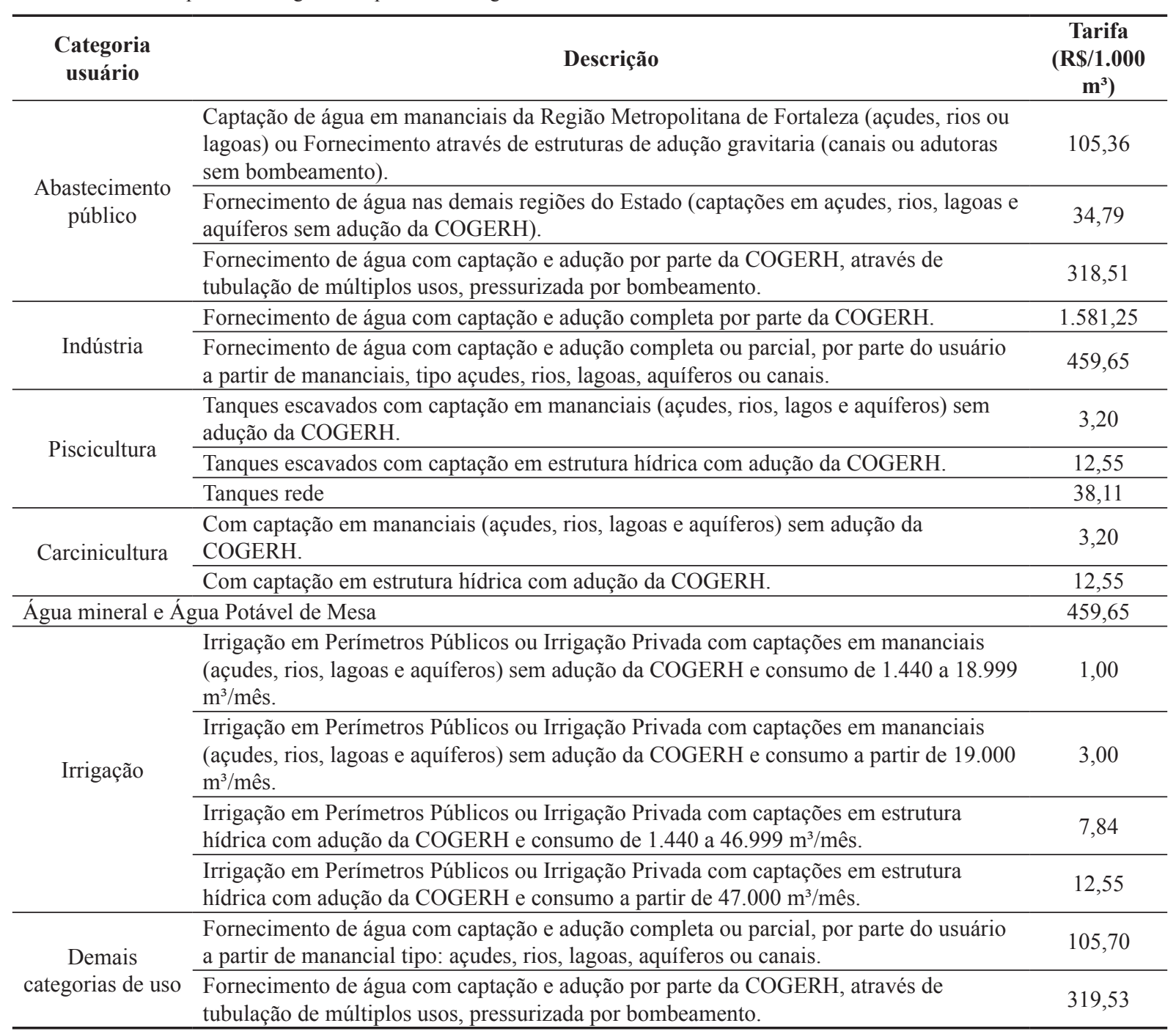

FONTE: Ceará (2013). 
TABELA 5 - Arrecadação setorial total no período 2008-2013 na BCH do Rio Paraíba do Sul (Valores em R\$ 1,00).

\begin{tabular}{cccc}
\hline Setor de arrecadação & Estimativa de arrecadação & Valores pagos & \% valor pago \\
\hline Indústria & $19.244 .066,66$ & $27.725 .646,69$ & $49,58 \%$ \\
Irrigação & $151.699,02$ & $65.092,84$ & $0,12 \%$ \\
Dessedentação e Criação Animal & 245,43 & 312,61 & $0,001 \%$ \\
Mineração & $109.809,51$ & $96.961,36$ & $0,17 \%$ \\
Outros Usos & $243.516,01$ & $467.533,50$ & $0,84 \%$ \\
Saneamento & $28.685 .348,29$ & $27.565 .547,04$ & $49,29 \%$ \\
Totais & $\mathbf{4 8 . 4 3 4 . 6 8 4 , 9 2}$ & $\mathbf{5 5 . 9 2 1 . 0 9 4 , 0 4}$ & $\mathbf{1 0 0 , 0 0 \%}$ \\
\hline
\end{tabular}

FONTE: adaptado de ANA (2013).

A arrecadação total neste período foi de aproximadamente R\$ 56 milhões, com uma média mensal de R\$ 1,165 milhões. O setor que mais contribui com a arrecadação foi o setor industrial $(49,56 \%)$, seguido do setor de saneamento (49,27\%) e dos demais setores $(1,17 \%)$, tais como a irrigação, a mineração e outros usos. Ainda, é possível identificar pela Tabela 3 que a arrecadação foi superior em cerca de $15,50 \%$ à estimada para o período.

A Tabela 6 apresenta a arrecadação por setor de usuários na $\mathrm{BCH}$ dos Rios $\mathrm{PCJ}$ referente ao período de exercício de 2006 a 2011.
A arrecadação total no período foi de $\mathrm{R} \$$ 91.653.485,67, com uma média anual e mensal de R\$ 15.275.581,28 e R\$ 1.272.965,11, respectivamente. O tipo de uso que mais contribuiu com a arrecadação foi o setor de saneamento $(82,71 \%)$, seguido do setor industrial $(13,75 \%)$ e pelos demais setores $(3,54 \%)$. Ademais, é possível identificar que a arrecadação correspondeu a aproximadamente $96,71 \%$ do valor estimado para o período.

A Tabela 7 apresenta a arrecadação setorial na BHSF nos anos de 2010 a 2011.

TABELA 6 - Arrecadação setorial total no período 2006-2011 na BCH PCJ (Valores em R\$ 1,00).

\begin{tabular}{cccc}
\hline Setor de arrecadação & Estimativa de arrecadação & Valores pagos & \% valor pago \\
\hline Indústria & $13.042 .453,37$ & $12.603 .671,59$ & $13,75 \%$ \\
Irrigação & $85.493,86$ & $68.497,89$ & $0,07 \%$ \\
Criação Animal & 80,00 & 113,91 & $0,00 \%$ \\
Aquicultura & 141,91 & 204,98 & $0,00 \%$ \\
Mineração & $17.706,14$ & $18.063,75$ & $0,02 \%$ \\
Outros Usos & $3.894 .691,90$ & $3.160 .500,95$ & $3,45 \%$ \\
Saneamento & $77.729 .433,39$ & $75.802 .432,60$ & $82,71 \%$ \\
Totais & $\mathbf{9 4 . 7 7 0 . 0 0 0 , 5 7}$ & $\mathbf{9 1 . 6 5 3 . 4 8 5 , 6 7}$ & $\mathbf{1 0 0 , 0 0 \%}$ \\
\hline
\end{tabular}

FONTE: adaptado de ANA (2013). 
TABELA 7 - Arrecadação setorial total no período 2010-2011 na BHSF (Valores em R\$ 1,00).

\begin{tabular}{cccc}
\hline Setor de arrecadação & Estimativa de arrecadação & Valores pagos & \% valor pago \\
\hline Indústria & $444.716,97$ & $270.067,47$ & $0,93 \%$ \\
Uso público & $2.697 .944,62$ & $1.451 .149,96$ & $4,98 \%$ \\
Diversos & $4.664 .534,34$ & $2.892 .566,72$ & $9,92 \%$ \\
Esgotamento sanitário & $2.977 .947,09$ & $2.796 .559,69$ & $9,59 \%$ \\
Abastecimento público & $58.744,89$ & $57.034,86$ & $0,20 \%$ \\
Irrigação & $3.055 .492,51$ & $2.339 .708,79$ & $8,03 \%$ \\
Mineração & $579.039,49$ & $523.584,04$ & $1,80 \%$ \\
Aquicultura & $60.204,55$ & $52.535,80$ & $0,18 \%$ \\
Outros Usos & $18.777 .576,48$ & $18.771 .682,53$ & $64,39 \%$ \\
Totais & $\mathbf{3 3 . 3 1 6 . 2 0 0 , 9 4}$ & $\mathbf{2 9 . 1 5 4 . 8 8 9 , 8 6}$ & $\mathbf{1 0 0 , 0 0 \%}$ \\
\hline
\end{tabular}

FONTE: adaptado de ANA (2013).

A arrecadação total no período foi de R\$ 29.154.889,86, com uma média anual e mensal de R\$ 14.577.444,93 e R\$1.214.787,07, respectivamente. Os tipos de uso que mais contribuíram com a arrecadação foram os outros usos $(64,39 \%)$, seguido do setor de diversos $(9,92 \%)$ e pelos demais setores $(25,69 \%)$, tais como abastecimento público, esgotamento sanitário, irrigação, mineração e outros usos. Ainda, é possível identificar pela Tabela 5, que a arrecadação correspondeu a aproximadamente $87,5 \%$ do valor estimado.

A Tabela 8 quantifica os montantes totais gerados com a arrecadação pelo uso da água na $\mathrm{BCH}$ do Rio Doce referente aos anos de 2012 e 2013.

TABELA 8 - Arrecadação total na BCH do Rio Doce nos anos de 2012 e 2013 (Valores em R\$1,00).

\begin{tabular}{ll}
\hline Ano & Arrecadação \\
\hline 2012 & $3.450 .856,88$ \\
2013 (até abril) & $1.459 .056,79$ \\
\hline Totais & $\mathbf{4 . 9 0 9 . 9 1 3 , 6 7}$ \\
\hline
\end{tabular}

FONTE: adaptado de ANA (2013).
A arrecadação total referente ao período foi de R\$ 4.909.913,67 para a BCH do Rio Doce. É importante notar que a cobrança é um instrumento recente e o $\mathrm{CBH}$ não dispõe de dados setoriais como ocorre em outras $\mathrm{BCH}$.

A Tabela 9 apresenta a arrecadação referente à cobrança pelo uso da água por setor no estado do Ceará relativo aos anos de 2011 e 2012.

A arrecadação total no período foi equivalente a R\$ 98.610.298,00, sendo o setor de maior contribuição o de abastecimento público (62,50\%), seguido pelo setor industrial $(35,43 \%)$ e demais setores $(2,07 \%)$. É possível visualizar um aumento de 2012, em relação ao ano anterior, de $34,69 \%$. Isso ocorreu em virtude do aumento do consumo da água, devido à brusca seca que afligiu o Estado do Ceará no período. Além disso, foram captados novos clientes com o interesse de utilizar a água bruta por uma tarifa mais acessível, como usuários, principalmente do setor industrial (COGERH, 2012).

A COGERH, afirma que os objetivos iniciais referem-se à cobertura dos custos de operação e de manutenção nas bacias estaduais. Dessa forma, a cobrança exclui eventuais reflexões sobre elasticidade-preço da demanda e, por conseguinte, sobre possíveis metas incitativas da cobrança. Assim, a cobrança no Estado, 
TABELA 9 - Arrecadação no Estado do Ceará no período 2011-2011 (Valores em R\$ 1,00).

\begin{tabular}{cccc}
\hline Usuário & $\mathbf{2 0 1 2}$ & $\mathbf{2 0 1 1}$ & $\mathbf{\%}$ total \\
\hline Abastecimento Público & $32.918 .389,00$ & $28.715 .875,00$ & $62,50 \%$ \\
Indústria & $22.203 .429,00$ & $12.730 .299,00$ & $35,43 \%$ \\
Piscicultura & $43.168,00$ & $100.403,00$ & $0,15 \%$ \\
Carcinicultura & $135.330,00$ & $21.994,00$ & $0,16 \%$ \\
Irrigação & $849.250,00$ & $353.361,00$ & $1,22 \%$ \\
Água mineral & $187.798,00$ & $59.252,00$ & $0,25 \%$ \\
Demais usos & $256.669,00$ & $35.079,00$ & $0,30 \%$ \\
\hline Totais & $\mathbf{5 6 . 5 9 4 . 0 3 5 , 0 0}$ & $\mathbf{4 2 . 0 1 6 . 2 6 3 , 0 0}$ & $\mathbf{1 0 0 , 0 0 \%}$ \\
\hline
\end{tabular}

FONTE: adaptado de COGERH (2012).

ao contrário do disposto na PNRH (Brasil, 1997), gera um financiamento de medidas visando à expansão da oferta ao invés de controlar e de influenciar a demanda.

Os investimentos realizados pelas respectivas agências nas BCH PBS e PCJ procedentes da cobrança pelo uso da água são apresentados na Tabela 10. Os relatórios das demais $\mathrm{BCH}$, no momento, não estão disponibilizados pelos respectivos comitês.

Os recursos arrecadados com a cobrança e com o programa de investimentos do Plano de Recursos Hídricos da BCH PBS representam 13,4 \% do valor estimado das ações necessárias para a recuperação da bacia (AGEVAP, 2012). Por sua vez, os investimentos aplicados à $\mathrm{BCH}$ PCJ com recursos oriundos da cobrança federal (já com contrapartida) e do FEHIDRO (Fundo Estadual de Recursos Hídricos - SP), representou em 2006, 12,95\% do previsto (IRRIGART, 2007).

A maior parcela de investimentos realizados nessas $\mathrm{BCH}$ é relativa a ações estruturais que visam à recuperação dos corpos hídricos, como por exemplo, a construção de estações de tratamento de esgoto e os sistemas de coleta e de afastamento de efluentes sanitários, bem como programas de controle de perdas. É válido ressaltar que tais ações são realizadas exclusivamente de acordo com o estabelecido como prioridade pelo Plano de Bacia, conforme disposto na Lei 9.433 (Brasil, 1997).

TABELA 10 - Investimentos realizados nas BCH PBS e PCJ.

\begin{tabular}{lll}
\hline BCH & Descrição do investimento & $\mathbf{\%}$ \\
\hline & Tratamento de Esgoto & $48,07 \%$ \\
& Reflorestamento & $0,31 \%$ \\
\multirow{2}{*}{ PCJ (2006-2013) } & Ações Apoio Gestão & $7,87 \%$ \\
& Controle de Perdas & $36,58 \%$ \\
& Outras ações & $7,18 \%$ \\
\cline { 2 - 3 } & Total & $\mathbf{1 0 0 , 0 0 \%}$ \\
\hline \multirow{2}{*}{ PBS (2003-2011) } & Recuperação da Qualidade Ambiental & $88,09 \%$ \\
& Gerenciamento de Recursos Hídricos & $1,31 \%$ \\
& Proteção e Aproveitamento dos Recursos Hídricos & $3,59 \%$ \\
& Atendimento ao Contrato de Gestão & $7,01 \%$ \\
\cline { 2 - 3 } & Total & $\mathbf{1 0 0 , 0 0 \%}$ \\
\hline
\end{tabular}

FONTE: CEIVAP (2013b), Agência PCJ (2013). 


\section{Conclus̃̃es}

Em todas as BCH de águas com domínio da União, é possível verificar que o modelo de cobrança pelo uso da água segue a mesma estruturação, considerando todos os usos de água na bacia. Ainda, cada parcela considera os volumes utilizados, o preço unitário pelo uso, os coeficientes próprios e relativos à gestão da $\mathrm{BCH}$. Por outro lado, a cobrança pelo uso da água bruta no Estado do Ceará, pioneira no Brasil e metodologicamente diferenciada em relação às outras estruturas, apresenta-se baseada no atual sistema de tarifação.

A metodologia e os critérios de cobrança aprovados pelo Comitê PCJ apresentam um maior detalhamento que aqueles aprovados pelos demais comitês, beneficiando-se já da experiência adquirida, pode-se dizer. Ao prever mecanismos de compensação para usuários que lancem efluentes com qualidade superior àquela do corpo hídrico ou que invistam em obras e em ações contempladas no Plano da Bacia, possibilitam-se investimentos com recursos próprios dos usuários e em ações de melhoria da qualidade, da quantidade de água e do regime fluvial, que resultem na sustentabilidade ambiental da $\mathrm{BCH}$. Assim, pode-se afirmar que o mecanismo da progressividade pode aumentar a aceitação da cobrança e reduz o impacto econômico imediato sobre os usuários.

A arrecadação setorial apresentou-se variável em todas $\mathrm{BCH}$, no entanto, pode-se citar como setores com maior potencial de arrecadação o de saneamento básico e industrial, respectivamente, devido às quantidades empregadas, tanto para captação, quanto para consumo e para o lançamento de cargas poluentes nos corpos hídricos.

Além disso, os investimentos realizados com recursos obtidos com a cobrança nas $\mathrm{BCH}$ PBS e BCH PCJ, representam, respectivamente, $13,4 \%$ e $12,95 \%$ (em 2006) dos totais previstos, sendo aplicados, em sua maioria, a ações estruturais envolvendo a recuperação dos recursos hídricos, tais como estações de tratamento e redes de coleta e afastamento de efluentes. Contudo, hoje se tem a percepção de que não se pode depositar sobre a cobrança pelo uso da água, toda a responsabilidade pela total recuperação dos recursos hídricos. É fundamental a articulação entre diferentes atores e o estímulo da busca de outras fontes de recursos, como os fundos de recursos hídricos. Assim, os escassos recursos arrecadados com a cobrança devem ser utilizados para preparar a $\mathrm{BCH}$ para aproveitar as oportunidades de investimentos oriundas de outras fontes de recursos.

Assim, este estudo propiciou um entendimento dos mecanismos adotados em águas com domínio da União. No entanto, o processo de implantação deve considerar características próprias de cada $\mathrm{BCH}$ e envolver o máximo possível a sociedade na tomada de decisões, principalmente, em relação ao destino dos recursos financeiros arrecadados.

\section{Referências}

Agência Nacional de Águas (ANA). Nota técnica no 06/2010/ $S A G-A N A$ : cobrança pelo uso de recursos hídricos na bacia hidrográfica do Rio São Francisco. Brasília: ANA, 2010.

Agência Nacional de Águas (ANA). Serviços. Cobrança e Arrecadação. Disponível em: $<$ http://www2.ana.gov.br/Paginas/ servicos/cobrancaearrecadacao/cobrancaearrecadacao.aspx $>$. Acesso em: 11 nov. 2013.

Agência PCJ. Informações das bacias. Disponível em: <http:// www.agenciapcj.org.br/novo/informacoes-das-bacias $>$. Acesso em: 11 nov. 2013.
Agência PCJ. Cobrança pelo uso da água. Folder: cobrança pelo uso dos recursos hídricos nas bacias PCJ. Agência PCJ: 2013. Disponível em: <http://www.agenciapcj.org.br/novo/ instrumentos-de-gestao/cobranca-pelo-uso-da-agua $>$. Acesso em: 11 mar. 2014.

Associação pró-gestão das águas da Bacia Hidrográfica do Rio Paraíba do Sul (AGEVAP). Avaliação da implementação da cobrança pelo uso de recursos hídricos de domínio da União na Bacia Hidrográfica do Rio Paraíba do Sul: período 2003/2011. AGEVAP: 2012. Disponível em: <http://arquivos.ana.gov.br/ 
institucional/sag/CobrancaUso/Cobranca/RelatorioAvalImplCobPBS03_11.pdf $>$. Acesso em: 10 mar. 2014.

Braga, B. et al. A reforma Institucional do setor de Recursos Hídricos. In: Rebouças, A. C.; Braga, B.; Tundisi, J. G. Águas Doces no Brasil: Capital Ecológico, Uso e Conservação. São Paulo: Escrituras Editora,3. ed., p. 639-676, 2006.

Brasil. Lei $n^{\circ} 9.433$, de 08 de janeiro de 1997. Institui a Política Nacional de Recursos Hídricos, cria o Sistema Nacional de Gerenciamento de Recursos Hídricos, regulamenta o inciso XIX do art. 21 da Constituição Federal, e altera o art. $1^{\circ}$ da lei $\mathrm{n}^{\circ} 8001$, de 13 de março de 1990, que modificou a Lei $\mathrm{n}^{\circ}$ 7990 de 28 de dezembro de 1989. Disponível em: <http:// www.planalto.gov.br/ccivil_03/Leis/L9433.htm>. Acesso em: 03 set. 2013.

Brasil. Lei $n^{\circ}$ 9.984, de 17 de julho de 2000. Dispõe sobre a criação da Agência Nacional de Águas - ANA, entidade federal de implementação da Política Nacional de Recursos Hídricos e de coordenação do Sistema Nacional de Gerenciamento de Recursos Hídricos, e dá outras providências. Disponível em: $<$ http://www.planalto.gov.br/ccivil_03/Leis/L9984.htm>. Acesso em: 03 set. 2013.

Carvalho, G. B. B.; Thomas, P. T.; Acselrad M. V: A cobrança pelo uso da água nas bacias dos rios Paraíba do Sul e PCJ: In: Simpósio Brasileiro de Recursos Hídricos, 27. Anais... São Paulo: ABRH, 2007.

Ceará. Decreto $n^{\circ} 31.195$, de 16 de abril de 2013. Dispõe sobre a cobrança pelo uso dos recursos hídricos superficiais e subterrâneos de domínio do Estado do Ceará ou da União por delegação de competência, e dá outras providências. Disponível em: <http://www.rcambiental.com.br/Atos/ver/ DEC-CE-31195-2013>. Acesso em: 11 nov. 2013.

CEIVAP - Comitê de Integração da Bacia Hidrográfica do Rio Paraíba do Sul. Deliberação CEIVAP $n^{\circ}$ 65/2006, de 28 de setembro de 2006. Estabelece mecanismos e propõe valores para a cobrança pelo uso de recursos hídricos na bacia hidrográfica do rio Paraíba do Sul, a partir de 2007. Disponível em: <www. ceivap.org.br/downloads/Deliberacao\%20CEIVAP\%2065\%20-\%202006\%20Cobranca\%20-\%20aprovada\%20Plenaria\%20 CEIVAP\%20Resende\%20-\%2028-09-06.pdf $>$. Acesso em: 06 out. 2013.

CEIVAP - Comitê de Integração da Bacia Hidrográfica do Rio Paraíba do Sul. Gestão da Bacia. Dados Gerais. 2013a. Disponível em: $<$ http://www.ceivap.org.br/dadosgerais.php $>$. Acesso em: 11 nov. 2013a.

CEIVAP - Comitê de Integração da Bacia Hidrográfica do Rio Paraíba do Sul. Arrecadação/Investimentos. Recursos
Arrecadados/Investidos. 2013b. Disponível em: $<$ http://www. ceivap.org.br/arrecadainveste.php>. Acesso em: 11 nov. 2013.

Comitê da Bacia Hidrográfica do Rio Doce (CBH-DOCE). Bacia do Rio Doce. Caracterização da Bacia. Disponível: $<\mathrm{http}$ ://www.riodoce.cbh.gov.br/bacia_caracterizacao.asp $>$. Acesso em: 11 nov. 2013.

Comitê da Bacia Hidrográfica do Rio Doce (CBH-DOCE). Deliberação CBH-DOCE $\mathrm{n}^{\circ} 26$, de 31 de março de 2011. Dispõe sobre mecanismos e valores de cobrança pelo uso de recursos hídricos na bacia hidrográfica do rio Doce. Disponível: $<$ http://www.riodoce.cbh.gov.br/>. Acesso em: 11 nov. 2013.

Comitê da Bacia Hidrográfica do Rio São Francisco (CBHSF). A Bacia:Principais características. Disponível em: <http:// cbhsaofrancisco.org.br/\#>. Acesso em: 11 nov. 2013.

Comitê da Bacia Hidrográfica do Rio São Francisco (CBHSF). Deliberação CBHSF $n^{\circ}$ 40, de 31 de outubro de 2008. Estabelece mecanismos e sugere valores de cobrança pelo uso de recursos hídricos na bacia hidrográfica do rio São Francisco. Disponível em: $<$ http://cbhsaofrancisco.org.br/\#>. Acesso em: 11 nov. 2013.

Comitês das Bacias Hidrográficas dos Rios Piracicaba, Capivari e Jundiaí (Comitês PCJ). Deliberação Conjunta $n^{\circ} 78$, de 05 de outubro de 2007. Aprova propostas de revisão dos mecanismos e de ratificação dos valores para a cobrança pelo uso dos recursos hídricos de domínio da União nas bacias hidrográficas dos rios Piracicaba, Capivari e Jundiaí e dá outras providências. Disponível em: <http://www.comitespcj.org. br/>. Acesso em: 11 nov. 2013.

Comitês das Bacias Hidrográficas dos Rios Piracicaba, Capivari e Jundiaí (Comitês PCJ). Deliberação dos Comitês PCJ $n^{\circ} 160$, de 14 de dezembro de 2012. Estabelece novos valores para os PUBs as cobranças pelo uso dos recursos hídricos nas bacias hidrográficas dos rios Piracicaba, Capivari e Jundiaí (Cobranças PCJ) e dá ouras providencias. Disponível em: $<$ http://www.comitespcj.org.br/images/Download/DelibComitesPCJ16012_ComRedacaoDelibComitesPCJ211-14.pdf>. Acesso em: 06 out. 2014.

Companhia de Gestão de Recursos Hídricos do Ceará (COGERH). Informações financeiras. Demonstrações contábeis 2012. Disponível em: <http://portal.cogerh.com.br/informacoes-financeiras $>$. Acesso em: 11 nov. 2013.

Forgiarini, F. R. Modelagem da cobrança pelo uso da água bruta para aplicação em escala real na bacia do Rio Santa Maria. Santa Maria, Dissertação (Mestrado em Engenharia Civil) - UFSM, 2006. 
FINEP; UFBA. Aspectos da relação entre a cobrança pelo uso da água e os setores elétrico e rural na bacia do Rio Paraíba do Sul. São Paulo, 2012. 668 p. (Relatórios).

Granziera, M. L. M. Direito de Águas: Disciplina Jurídica das Águas Doces. São Paulo: Atlas, 3. ed., 2006.

Instituto Brasileiro de Geografia e Estatística (IBGE). Censo 2010. Disponível em: <http://censo2010.ibge.gov.br/>. Acesso em: 11 nov. 2013.

IRRIGART - Engenharia e Consultoria em Recursos Hídricos. Bacias hidrográficas dos rios Piracicaba, Capivari e Jundiaí: situação dos recursos hídricos 2004/2006; relatório síntese. Piracicaba: FEHIDRO/PCJ/CBJ-PCJ, 2007. 75 p.
Lanna, A. E. L. Gestão das águas. Brasília: MMA, 1999.

Pompeu, C. T. Águas Doces no Direto Brasileiro. In: Rebouças, A. C.; Braga, B.; Tundisi, J. G. Águas Doces no Brasil: Capital Ecológico, Uso e Conservação. São Paulo: Escrituras, 3a ed. São Paulo: Escrituras Editora, p. 677-717, 2006.

Thomas, P.T. Proposta de uma Metodologia de Cobrança pelo Uso da Água vinculada à Escassez. Rio de Janeiro, Tese (Mestrado em Ciências em Engenharia Civil) - UFRJ, 2002.

Vianna, L. F. G. Proposta de modelo de cobrança de água bruta no Estado do Ceará: uma revisão do modelo atual. Fortaleza, Dissertação (Mestrado em Economia Rural) - UFCE, 2011. 